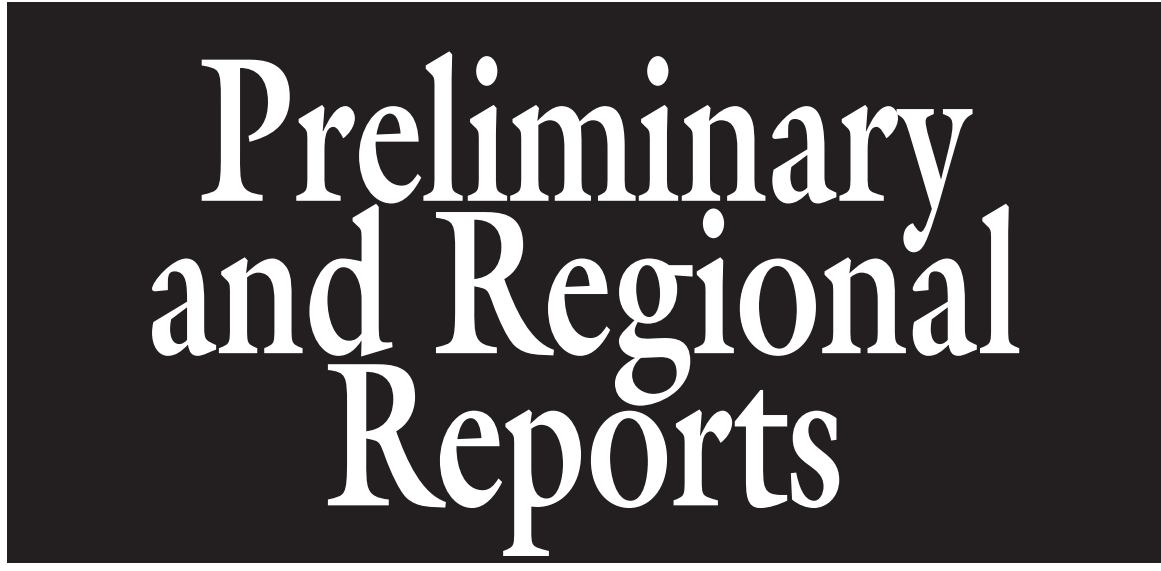

\title{
Two Reproductive Bud Thinning Alternatives for Cactus Pear
}

\author{
Jorge A. Zegbe ${ }^{1}$ and Jaime Mena-Covarrubias
}

AdDitionAl INDEX WORDs. Opuntia albicarpa, O. ficus-indica, fruit size

Summary. Cactus pear (Opuntia spp.) is an important Mexican fruit crop cultivated extensively (about 51,000 ha) in the semiarid highlands of Mexico. Fruit exports have increased in the last decade, but to fulfill these markets, fruit size must be enhanced. However, current hand thinning reduces yield, thus making it uneconomical for growers. The objective was to evaluate two reproductive bud (RB) thinning protocols in an effort to increase export fruit size without depressing cactus pear yield. Two experiments were conducted during the 2004 growing season with two cactus pear types: Cristalina (Opuntia albicarpa) and Rojo liso (Opuntia ficus-indica). In the first experiment, the treatments were no thinning (control) or keeping 4,8 , or $12 \mathrm{RBs}$ per cladode. In the second experiment, the treatments were no thinning (control), thinning every other bud along the cladode, and thinning two of every three buds along the cladode. In the first experiment, yield of Cristalina was reduced by $10.4 \%$ and $51.8 \%$ when eight or four RBs per cladode were retained, respectively. Mean fruit weight of Cristalina decreased with the most severe thinning treatment. Yield of Rojo liso was reduced when four RBs were retained per cladode. In the second experiment, yield of both cactus pear types was unaffected by the thinning treatments. Therefore, we recommend thinning every other bud along the cladode because it does not reduce yield and tends to improve marketable fruit in both cactus pear types. However, this thinning alternative should be tested in other commercial cactus pear types if growers are interested in export markets.

Instituto Nacional de Investigaciones Forestales, Agrícolas y Pecuarias, Campo Experimental Zacatecas, Apartado Postal No. 18, Calera de Víctor Rosales, Zacatecas, 98500, México

This research was funded in part by The Fundación Produce Zacatecas A.C., Ref. No. 02/FPZ/2001, and by The Consejo Nacional de Ciencia y Tecnología, Ref. No. 0007-2005-1_12448.

We thank Miguel and Valentín Nava-Félix, the owners of the orchard 'Rancho La Tunera.' We also extend our appreciation to Manuel González-Solís, Guadalupe de la Cruz-Rodríguez, Salvador Rosas-Gallegos, and Miguel Juárez-Aguilar for their field assistance. We are grateful to Stewart Field (Charles Sturt University, Australia), Tessa M. Mills (HortResearch, New Zealand), Joel Corrales-García (Universidad Autónoma Chapingo, Mexico), and Eulogio Pimienta-Barrios (Universidad de Guadalajara, Mexico) for their critical comments on the manuscript.

${ }^{1}$ Corresponding author. E-mail: jzegbe@zacatecas. inifap.gob.mx.

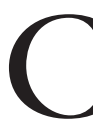
actus pear is a Mexican fruit crop cultivated extensively (about 51,000 ha) in the semiarid highlands of central Mexico. This crop has gained economic importance in countries of Europe, America, Asia, and Africa (Basile, 2001). In Mexico, cactus pear production systems have an important social impact in lower local market competitiveness compared with other commodities (Rincón-Valdez et al., 2004). However, the exported volumes in the last decade have alleviated, in part, the low economic return. Therefore, fruit suitable for export is now the goal for Mexican growers.

As for other fruit crops exemplified by apple [Malus $\times$ domestica (Kilili et al., 1996)], fruit size of cactus pear depends on orchard management practices during the growing season (Inglese, 1995) and on the cactus pear types (Fernández-Montes et al., 2000). Furthermore, irrigation (Zegbe et al., 2006), nutrition (Nerd et al., 1993), and crop load (Inglese et al., 1995) have also been shown to affect the fruit size of cactus pear. In view of export markets, fruit thinning is a common practice to increase fruit size and to speed up ripening (Inglese, 1995; Inglese et al., 1995). The reproductive bud $(\mathrm{RB})$ thinning threshold has been established at six fruit per cladode (Gugliuzza et al., 2002; Inglese, 1995; Inglese et al., 1995). However, this thinning protocol reduces fruit yield in Mexican commercial cactus pear types. Therefore, growers refuse to apply this protocol with the corresponding negative impact on fruit size. Consequently, the aim of this study was to evaluate a RB thinning alternative to increase export size fruit without affecting fruit yield on commercial cactus pear types.

\section{Materials and methods}

EXPERIMENTAL SITE, GeNeTIC MATERIAL, AND ORCHARD MANAGEMENT. The experiments were conducted from Mar. to Oct. 2004 in a commercial orchard (Rancho la Tunera) in Jerez, Mexico (lat. $22^{\circ} 32^{\prime} \mathrm{N}$, long. $103^{\circ} 03^{\prime} \mathrm{W}$, elevation $1976 \mathrm{~m}$ ). The experimental site has an

\begin{tabular}{llll}
\hline $\begin{array}{l}\text { Units } \\
\begin{array}{l}\text { To convert U.S. } \\
\text { to SI, multiply by }\end{array}\end{array}$ & U.S. unit & SI unit & $\begin{array}{l}\text { To convert SI } \\
\text { to U.S., multiply by }\end{array}$ \\
\hline 0.4047 & acre(s) & $\mathrm{ha}$ & 2.4711 \\
0.3048 & $\mathrm{ft}$ & $\mathrm{m}$ & 3.2808 \\
2.54 & inch(es) & $\mathrm{cm}$ & 0.3937 \\
25.4 & inch(es) & $\mathrm{mm}$ & 0.0394 \\
0.4536 & $\mathrm{lb}$ & $\mathrm{kg}$ & 2.2046 \\
28.3495 & $\mathrm{oz}$ & $\mathrm{g}$ & 0.0353 \\
$\left({ }^{\circ} \mathrm{F}-32\right) \div 1.8$ & ${ }^{\circ} \mathrm{F}$ & ${ }^{\circ} \mathrm{C}$ & $\left(1.8 \times{ }^{\circ} \mathrm{C}\right)+32$
\end{tabular}


annual mean temperature of $25.7^{\circ} \mathrm{C}$ and $482 \mathrm{~mm}$ of precipitation, with $62 \%$ of the rain occurring between July and October. The orchard soil is clay loam with $1.63 \%$ organic matter and 7.1 soil pH. Two types of cactus pears, planted in 2000, were used in these experiments: Cristalina (late-maturing, white-pulped type) and Rojo liso (early-maturing, red-pulped type). Tree spacing was $5 \times 3 \mathrm{~m}$ and plants were trained to the open vase form. Except for RB thinning, trees received cladode pruning, fertigation, and pest control as is standard for commercial production in this region. Drip irrigation was provided weekly based on a soil-water balance. Trees were fertilized in the first four irrigation events with $90 \mathrm{~N}-13.1 \mathrm{P}-24.9 \mathrm{~K}$. The first half of the nitrogen $(\mathrm{N})$ and total phosphorus and potassium were applied with the first four irrigations; the remaining half of $\mathrm{N}$ was supplied via fertigation 4 weeks after fruit harvest.

Expт. 1. This trial examined the effect of RB load per cladode as proposed by Inglese et al. (1995). Sixteen plots (four plots per treatment) for each cactus pear type were chosen. Each plot had three uniform trees that were randomly allocated to one of the four RB thinning treatments. The treatments were: no thinning considered as control $(\mathrm{C})$ or retaining 4,8 , or 12 RBs per mature cladode (4RB, 8RB, and 12RB, respectively).

Expt. 2. In this case, 12 plots (three plots per treatments) for each cactus pear type were used. Each plot had three uniform trees that were randomly allocated to one of the three $\mathrm{RB}$ thinning treatments. The treatments were: no thinning considered as control (C), thinning every other bud along of the cladode (T1), and thinning two of every three buds along the cladode (T2). Twin RBs were manually removed except for the control treatment. One or two reproductive buds were then thinned out alternately along of the cladode (Fig. 1). In both experiments, RBs were hand-thinned $10 \mathrm{~d}$ before blossom time, which occurred on 15 and 20 Apr. for Rojo liso and Cristalina, respectively.

Both experiments were conducted in a complete randomized design. Thinning treatments were repeated four times. The minimum number of replication for detecting significant differences $(P<0.05)$ among treatments was determined according to Petersen (1994).

DATA COLLECTION AND ANALYSIS. The information was collected from the central tree of each plot. Harvest started on 19 July (96 d after full bloom) and on 6 Aug. (109 d after full bloom) for Rojo liso and Cristalina, respectively. The fruit were collected at export harvest maturity, when peel color is reddish-green and yellowishgreen for Rojo liso and Cristalina, respectively. Harvest was done over four and seven events for Rojo liso and Cristalina, respectively. Fruit from each tree were harvested, graded by equatorial diameter $(1>7.0 \mathrm{~cm}, 2=6.0-7.0$ $\mathrm{cm}, 3=5.0-5.9 \mathrm{~cm}, 4=4.1-4.9 \mathrm{~cm}$, and $5=3.5-4.0 \mathrm{~cm}$ ), counted, and total weight of all fruit was measured as gross yield. Mean fresh weight of fruit was calculated by dividing the gross yield by number of fruit per tree. The data were analyzed by a complete randomized model using the analysis of variance (ANOVA) procedure of SAS (version 9.1; SAS Institute, Cary, NC). To stabilize the variance, the variables expressed in percentage (fruit categories), and in discrete units (fruit number) were arcsine and square-root transformed, respectively. Means are reported after back transforming. Treatment means were separated by the Tukey's Studentized range test at $P \leq 0.05$.

\section{Results and discussion}

Expт. 1. The highest yield was produced when 12RB were retained per cladode of Cristalina (Table 1). This increase was due to a second RB reflux (reflowering) as reflected in the fruit number collected at harvest. Fruit number for control trees and 12RB trees was 345 and 433, respectively. A reflowering phenomenon occurs when RB thinning is applied before bloom (Inglese, 1995), resulting from a change in hormonal balance and favorable air temperatures (Inglese et al., 1998). Our thinning treatments were applied $10 \mathrm{~d}$ before bloom. A similar reflowering pattern has been observed on cactus pear trees experiencing deficit irrigation and prebloom bud removal (Zegbe et al., 2006). In contrast, yield of Cristalina was reduced by $51 \%$ in $4 \mathrm{RB}$ trees compared with control trees as result of thinning severity, as seen in other fruit crops (Schupp et al., 2008). Mean fruit weight

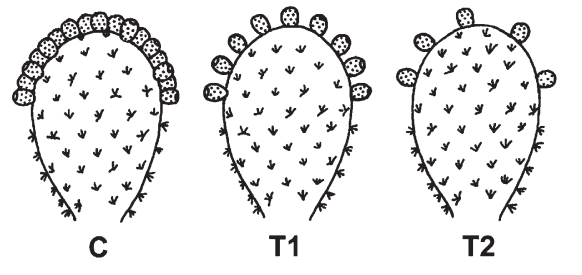

Fig. 1. Reproductive bud thinning treatments applied to two cactus pear types in Expt. 2 at Jerez, Mexico in 2004. The treatments were: no thinning considered as control (C), thinning every other bud along the cladode (T1), and thinning two out of every three buds along the cladode (T2).

increased by about $24 \%$ in $8 \mathrm{RB}$ trees compared with control trees. However, the most severe RB thinning treatment (4RB) did not enhance fruit size (Table 1 ). The percentage of fruit with an equatorial diameter between 6.0 and $7.0 \mathrm{~cm}$ (the best fruit for commercial trade) was higher in $4 \mathrm{RB}$ and $8 \mathrm{RB}$ trees than in $12 \mathrm{RB}$ and control trees (Table 1 ). Fruit of category 3 and 4 tended to reduce in $8 \mathrm{RB}$ and $4 \mathrm{RB}$ trees compared with $12 \mathrm{RB}$ and control trees (Table 1 ). Fruit with equatorial diameter lower than $4.1 \mathrm{~cm}$ or higher than 7.0 , and blemished fruit was the same among treatments (Table 1).

Yield of Rojo liso was lower in $4 \mathrm{RB}$ treatment compared with the other three treatments (Table 1). Furthermore, when compared with control trees, yield was reduced by $8.6 \%, 30.8 \%$, and $57.6 \%$ in $12 \mathrm{RB}$, $8 \mathrm{RB}$, and $4 \mathrm{RB}$ trees, respectively. This reduction indicates that Rojo liso is more sensitive to this RB thinning than Cristalina (Table 1 ). Although not significant, compared with control and $12 \mathrm{RB}$ trees, $4 \mathrm{RB}$ and $8 \mathrm{RB}$ trees tended to increase the fruit size in category 2 , whereas the opposite was observed in the fruit of category 4 in the same treatments (Table 1). Fruit in categories 3 and 5 , blemished fruit, and mean fruit weight were the same among treatments (Table 1).

Our findings partially agree with those of Gugliuzza et al. (2002), Inglese (1995), and Inglese et al. (1995) because the maximum fruit size was achieved with $8 \mathrm{RB}$ treatment in Cristalina trees instead of $6 \mathrm{RB}$ treatment in 'Gialla' trees (Inglese et al., 1995). In contrast, Rojo liso 
fruit size seems to be insensitive to this RB manipulation (Table l). Differential response of fruit size between Rojo liso and Cristalina suggests differences in genetic crop load rather than the number of normal seeds. Fruit growth potential has been attributed to the number of normal seeds (Inglese et al., 1995). However, the number of seeds in Rojo liso is relative higher $(4.8 \%)$ than in Cristalina, having both types the same abortive seeds (Fernández-Montes et al., 2000). Furthermore, the most severe thinning treatment $(4 R B)$ might have induced an undesirable competition for carbohydrates between developing fruit and other vegetative structures, limiting final fruit size.

Compared with control treatment, $8 \mathrm{RB}$ treatment promoted more than 2 -fold fruit of category 2 in both cactus pear types (Table 1), but additionally, $4 \mathrm{RB}$ and $8 \mathrm{RB}$ treatments promoted the highest percentage of cash value fruit (having equatorial diameter $>5.0 \mathrm{~cm}$ ) in both types, which is important for domestic consumers and export markets. The percentage values [minimum significant difference $(\mathrm{MSD})=13.1 \%$ ] for Cristalina were: $87.4 \%, 85.7 \%, 96.5 \%$, and $96.7 \%$ for control, $12 \mathrm{RB}, 8 \mathrm{RB}$, and $4 \mathrm{RB}$ treatments, respectively. The corresponding values $(\mathrm{MSD}=11.9 \%)$ for Rojo liso in the same order were: $68.1 \%, 71.0 \%, 75.6 \%$, and $83.6 \%$, respectively.

EXPT. 2. In this experiment, we have proposed another $\mathrm{RB}$ thinning criterion as an alternative to the current thinning method reported in the first experiment (Inglese et al., 1995). Yield of Cristalina and Rojo liso was unaffected by the thinning treatments. However, although not significant compared with control trees, yield of Cristalina tended to reduce by about $12 \%$ and $16.4 \%$ with the first and second thinning treatment, respectively (Table 2), while yield of Rojo liso was reduced by about 13\% and $24 \%$ with the first and second thinning treatment, respectively ( $\mathrm{Ta}-$ ble 2). Fruit size distribution was not altered by the RB treatments in Cristalina (Table 2). However, fruit of category 3 was increased in Rojo liso by the second treatment (Table 2). Similarly to the first experiment, the accumulated percentage of marketable fruit (fruit categories with equatorial diameter $\geq 5.0 \mathrm{~cm}$ ) tended to increase in both $\mathrm{RB}$ thinning treatments compared with the control trees in both cactus pear types. Yield values $(\mathrm{MSD}=14.7 \%)$ for Cristalina were: $85 \%, 91 \%$, and $93.4 \%$ for control, the first, and the second thinning treatment, respectively. In the same order, the corresponding values $(\mathrm{MSD}=17.1 \%)$ for Rojo liso were

Table 1. Effect of the number of reproductive buds retained per cladode (RBC) on yield, mean fruit weight (MFW), fruit size distribution, and blemished fruit (BF) of Cristalina-type and Rojo liso-type cactus pear at Jerez, Mexico in 2004.

\begin{tabular}{|c|c|c|c|c|c|c|c|c|}
\hline \multirow[b]{2}{*}{ RBC (no.) } & \multirow{2}{*}{$\begin{array}{c}\text { Yield } \\
(\mathrm{kg} / \text { tree })^{\mathrm{z}}\end{array}$} & \multirow{2}{*}{$\begin{array}{l}\text { Mean fruit } \\
\text { wt }(\mathrm{g})^{\mathrm{z}}\end{array}$} & \multicolumn{6}{|c|}{ Fruit size distribution $(\%)^{\mathrm{y}}$} \\
\hline & & & 1 & 2 & 3 & 4 & 5 & BF \\
\hline \multicolumn{9}{|c|}{ Cristalina type } \\
\hline 12 & $62.7 \mathrm{a}$ & $144.4 \mathrm{~b}$ & $0.4 \mathrm{a}$ & $26.9 \mathrm{~b}$ & $58.4 \mathrm{a}$ & $13.4 \mathrm{a}$ & $0.1 \mathrm{a}$ & $0.8 \mathrm{a}$ \\
\hline 8 & $43.3 \mathrm{ab}$ & $172.8 \mathrm{a}$ & $1.2 \mathrm{a}$ & $52.6 \mathrm{a}$ & $42.7 \mathrm{a}$ & $3.0 \mathrm{a}$ & $0.1 \mathrm{a}$ & $0.4 \mathrm{a}$ \\
\hline 4 & $23.3 \mathrm{~b}$ & $162.1 \mathrm{ab}$ & $0.3 \mathrm{a}$ & $48.5 \mathrm{a}$ & $48.0 \mathrm{a}$ & $2.8 \mathrm{a}$ & $0.0 \mathrm{a}$ & $0.4 \mathrm{a}$ \\
\hline 12 & $46.9 \mathrm{a}$ & $116.3 \mathrm{a}$ & 0.0 & $08.3 \mathrm{a}$ & $62.7 \mathrm{a}$ & $28.1 \mathrm{a}$ & $0.5 \mathrm{a}$ & $0.4 \mathrm{a}$ \\
\hline 8 & $35.5 \mathrm{ab}$ & $122.0 \mathrm{a}$ & 0.0 & $12.7 \mathrm{a}$ & $62.8 \mathrm{a}$ & $23.3 \mathrm{ab}$ & $0.5 \mathrm{a}$ & $0.7 \mathrm{a}$ \\
\hline 4 & $21.8 \mathrm{~b}$ & $121.0 \mathrm{a}$ & 0.0 & $15.2 \mathrm{a}$ & $68.5 \mathrm{a}$ & $15.2 \mathrm{~b}$ & $0.3 \mathrm{a}$ & $0.8 \mathrm{a}$ \\
\hline
\end{tabular}

${ }^{\mathrm{z}} \mathrm{l} \mathrm{kg}=2.2046 \mathrm{lb}, \mathrm{l} \mathrm{g}=0.0353 \mathrm{oz}$.

${ }^{y}$ Fruit size classes determined by equatorial diameter: $1>7.0 \mathrm{~cm}, 2=6.0-7.0 \mathrm{~cm}, 3=5.0-5.9 \mathrm{~cm}, 4=4.1-4.9 \mathrm{~cm}$, and $5=3.5-4.0 \mathrm{~cm}(1 \mathrm{~cm}=0.3937$ inch $)$. Fruit greater than $5.0 \mathrm{~cm}$ are marketable.

${ }^{x}$ For each cactus pear type, means within a column followed by the same letter are not significantly different at $P \leq 0.05$ by Tukey's Studentized range test.

Table 2. Effects of reproductive bud thinning (RBT) on yield, mean fruit weight, fruit size distribution, and blemished fruit (BF) of Cristalina type and Rojo liso type cactus pear at Jerez, Mexico in 2004.

\begin{tabular}{|c|c|c|c|c|c|c|c|c|}
\hline \multirow[b]{2}{*}{$\mathrm{RBT}^{\mathrm{z}}$} & \multirow{2}{*}{$\begin{array}{c}\text { Yield } \\
(\mathrm{kg} / \text { tree })^{\mathrm{y}}\end{array}$} & \multirow[b]{2}{*}{ Mean fruit wt $(g)^{y}$} & \multicolumn{6}{|c|}{ Fruit size distribution $(\%)^{\mathrm{x}}$} \\
\hline & & & 1 & 2 & 3 & 4 & 5 & $\mathrm{BF}$ \\
\hline \multicolumn{9}{|c|}{ Cristalina type } \\
\hline $\mathrm{Tl}$ & $50.2 \mathrm{a}$ & $154.5 \mathrm{a}$ & $1.7 \mathrm{a}$ & $34.0 \mathrm{a}$ & $55.4 \mathrm{a}$ & $08.3 \mathrm{a}$ & $0.0 \mathrm{a}$ & $0.6 \mathrm{a}$ \\
\hline $\mathrm{T} 2$ & $47.8 \mathrm{a}$ & $158.3 \mathrm{a}$ & $0.3 \mathrm{a}$ & $45.8 \mathrm{a}$ & $47.4 \mathrm{a}$ & $04.8 \mathrm{a}$ & $0.0 \mathrm{a}$ & $1.7 \mathrm{a}$ \\
\hline \multicolumn{9}{|c|}{ Rojo liso type } \\
\hline $\mathrm{T} 2$ & $42.7 \mathrm{a}$ & $121.7 \mathrm{a}$ & 0.0 & $7.1 \mathrm{a}$ & $65.0 \mathrm{a}$ & $25.3 \mathrm{a}$ & $1.3 \mathrm{a}$ & $1.3 \mathrm{a}$ \\
\hline
\end{tabular}

${ }^{2}$ The treatments were: no thinning considered as control (C), thinning every other bud along the cladode (Tl), and thinning two out of every three buds along the cladode (T2).

$\mathrm{l} \mathrm{kg}=2.2046 \mathrm{lb}, 1 \mathrm{~g}=0.0353 \mathrm{oz}$.

${ }^{x}$ Fruit size classes determined by equatorial diameter: $1>7.0 \mathrm{~cm}, 2=6.0-7.0 \mathrm{~cm}, 3=5.0-5.9 \mathrm{~cm}, 4=4.1-4.9 \mathrm{~cm}$, and $5=3.5-4.0 \mathrm{~cm}(1 \mathrm{~cm}=0.3937$ inch $)$. Fruit greater than $5.0 \mathrm{~cm}$ are marketable.

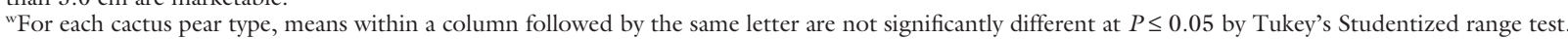


$59.4 \%, 64.1 \%$, and $72.1 \%$, respectively. The other fruit categories, mean fruit weight, and blemished fruit were unaffected by RB thinning treatments (Table 2).

Yield was not reduced and mean fruit weight tended to increase in both cactus pear types by using the proposed RB thinning protocol. Therefore, these results indicate that the proposed hand thinning alterative may promote better distribution and allocation of assimilates among the different cactus pear organs, mainly into the fruit. However, the experiments did not investigate the sinksource balance between reproductive and vegetative organs. Finally, compared with the thinning protocol recommended by Inglese et al. (1995) and used worldwide by the cactus pear growers, the thinning alternative described here, in the second experiment, has the following benefits: It is easy to apply, less time consuming, because it is much easier to remove reproductive buds than fruit, and it tends to enhance fruit size without affecting yield.

\section{Conclusions}

We have presented two alternatives to manipulate the reproductive buds of cactus pear and their effects on fruit size and yield. From the results, we recommend thinning to no less than eight RBs per cladode or to thin every other bud along the cladode. However, based on the differential responses observed in both cactus pear types used in this study, both thinning protocols must be tested in other cactus pear types before being adopted by commercial cactus pear growers.

\section{Literature cited}

Basile, F. 2001. Economic aspects of Italian cactus pear production and market. J. Professional Assn. Cactus Dev. 4:31-46.

Fernández-Montes, M.R., C. MondragónJacobo, J. Luna-Vázquez, F. GutierrezAcosta, L.A. Sáenz-Quintero, J.A. ZegbeDomínguez, S.J. Méndez-Gallegos, and J.C. Martínez-González. 2000. Principales cultivares Mexicanos de nopal tunero. Instituto Nacional de Investigaciones Forestales, Agrícolas y Pecuarias, Centro de Investigación Regional Centro-Campo Experimental Norte de Guanajuato. Publicación Técnica No. 1.

Gugliuzza, G., P. Inglese, and V. Farina. 2002. Relationship between fruit thin ning and irrigation on determining fruit quality of cactus pear (Opuntia ficusindica) fruits. Acta Hort. 581:205-209.

Inglese, P. 1995. Orchard planting and management, p. 78-91. In: G. Barbera, P. Inglese, and E. Pimienta-Barrios (eds.). Agro-ecology, cultivation, and uses of cactus pear. Food and Agriculture Organization of the United Nations. Plant Production and Protection. Paper 132.

Inglese, P., G. Barbera, T. La Mantia, and S. Portolano. 1995. Crop production, growth, and ultimate size of cactus pear fruit following fruit thinning. HortScience 30:227-230.

Inglese, P., I. Chessa, T. La Mantia, and G. Nieddu. 1998. Evolution of endoge- nous gibberellins at different stages of flowering in relation to return bloom of cactus pear (Opuntia ficus-indica L. Mill.). Scientia Hort. 73:45-51.

Kilili, A.W., M.H. Behboudian, and T.M. Mills. 1996. Composition and quality of 'Braeburn' apple under reduced irrigation. Scientia Hort. 67:1-11.

Nerd, A., R. Mesika, and Y. Mizrahi. 1993. Effect of $\mathrm{N}$ fertilizer on autumn floral flush and cladode $\mathrm{N}$ in prickly pear Opuntia ficus-indica (L.). Mill. J. Hort. Sci. 68:545-550.

Petersen, R.G. 1994. Agricultural field experiments. Design and analysis. 1st ed. Marcel Dekker, New York.

Rincón-Valdez, F., F.G. EchavarríaCháirez, A.F. Rumayor-Rodríguez, J. Mena-Covarrubias, A.G. Bravo-Lozano, E. Acosta-Díaz, J.L. Gallo-Dávila, and H. Salinas-González. 2004. Cadenas de sistemas agroalimentarios de chile seco, Durazno y frijol en el estado de Zacatecas: Una aplicación de la metodología ISNAR. Instituto Nacional de Investigaciones Forestales, Agrícolas y Pecuarias, Centro de Investigación Regional Norte CentroCampo Experimental Zacatecas. Publicación Especial No. 14.

Schupp, J.R., T.A. Baugher, S.S. Miller, R.M. Harsh, and K.M. Lesser. 2008. Mechanical thinning of peach and apple trees reduces labor input and increases fruit size. HortTechnology 18:660-670.

Zegbe, J.A., A. Serna, J. Mena, A.G. Bravo, and F.G. Echavarria. 2006. Cactus pear (Opuntia spp.) responses to reduced irrigation, p. 1-10. Intl. Symp. on Water and Land Mgt. for Sustainable Irr. Agr. Adana-Turkey, 4-8 Apr. 2006. 